\title{
LAS RELACIONES ENTRE ELCHE Y GRANADA (SS. XIV-XV). DE RIDWAN A LA GUERRA DE GRANADA
}

José Hinojosa Montalvo*

A partir de la conquista de Jaime II del reino de Murcia y la incorporación de las comarcas meridionales alicantinas al reino de Valencia y a la Corona de Aragón en virtud de la Sentencia Arbitral de Torrellas (1304) y de Elche (1305), el reino de Valencia no sólo vio incrementado su territorio sino que estas tierras pasaron a constituirse en frontera, no sólo de Castilla sino también del reino nazarí de Granada, y ello aun a pesar de no existir un contacto físico, directo, entre los reinos de Granada y Valencia. Entre ambos se interponía el reino de Murcia, escasamente poblado, que apenas podía servir de antemural a los ataques granadinos. Por eso para las autoridades y los habitantes de Elche, como los de Orihuela o Alicante, estas tierras tuvieron la consideración de frontera, porque, según la concepción de la época, la frontera era todo aquel espacio susceptible de sufrir una entrada del enemigo, bien de almogávares, bien de un ejército regular.

Los estudios de M. ${ }^{a}$ T. Ferrer i Mallol sobre La frontera amb l'Islam en el segle XIV en la gobernación de Orihuela ${ }^{1}$ son una aportación de primer orden y casi definitiva de las relaciones mantenidas por el reino de Valencia y Granada durante esta centuria y sus repercusiones en las comarcas del sur del reino, por lo que no insistiré en lo ya estudiado por la mencionada autora y simplemente recordaré desde la óptica militar las tres incursiones victoriosas del ejército nazarita de 1304, 1331 y 1332, y las cruzadas de Jaume II y de Alfonso IV contra Granada en 1309 y 1329-1334. Para Elche lo más trágico fueron los golpes asestados por Ridwan en 1331, en los que consiguió un gran botín en cautivos y animales, además de talar la huerta, proceso que se

* Universitat d'Alacant.

1. M.T. FERRER i MALLOL, La frontera amb l'Islam en el segle XIV. Cristians $i$ sarraïns al Pais Valencià, Barcelona, 1988. 
repitió en abril de 1332 cuando Ridwan volvió a asediar Elche, aunque en este caso los ilicitanos resistieron y el granadino tuvo que desistir de la empresa. En el futuro no hubo más ataques de esta envergadura contra Elche.

\section{EL ÚlTIMO TERCIO DEL SIGLO XIV}

En el limitado espacio de nuestra exposición el objetivo es, utilizando las actas municipales, analizar la actitud de las autoridades de Elche frente a las agresiones granadinas, que en estos siglos bajomedievales fueron una constante preocupación, no sólo de Elche sino de todas las demás localidades de la gobernación de Orihuela y demás comarcas meridionales del reino de Valencia, escenario de las correrías de los jinetes y almogávares andalusíes. El peligro no era imaginario sino real, aunque a finales de la Edad Media esta amenaza granadina no se concretó nunca en ataques masivos como el de Ridwan y todo quedó en incidentes aislados o simples amagos de invasión.

Conocemos la existencia de esta amenaza granadina a través de la correspondencia mantenida por el Consell de Elche con otras autoridades del reino, gracias a la utilización del sistema de avisos. Desde el siglo XIV, cuando la amenaza de piratas y corsarios se hizo más patente en el Mediterráneo occidental y, sobre todo, en las costas del reino de Valencia, las autoridades reales y municipales del reino pusieron en marcha diversos sistemas defensivos para protegerse de cualquier ataque enemigo, entre los que figuraban el armamento de embarcaciones o la creación de una red de escuchas, espías y atalayas en la zona frontera, aunque lo más eficaz fue la creación de un sistema de mensajería, que avisara con antelación de cualquier posible ataque granadino $^{2}$.

Son estos avisos los que nos permiten conocer en buena medida cuál era la percepción que las autoridades de Elche o de la gobernación de Orihuela tenían del "peligro granadino". Aunque las entradas por tierras de Elche menudearon en todo el siglo, la noticia más antigua conservada en las actas municipales data del 23 de marzo de 1371 cuando llegó al Consell ilicitano una misiva de Nicolau de Pròxida, gobernador general de Orihuela, avisando a las autoridades de que en Granada se preparaban tropas con la intención de invadir los reinos de Murcia y Aragón. Ante la noticia, los jurados dispusieron que se colocaran dos hombres de guardia en la Torre Blanca y se celebrara una procesión de dos días para alejar el peligro musulmán ${ }^{3}$.

2. A. DIAz BORRAs, Los orígenes de la piratería islámica en Valencia. La ofensioa musulmana trecentista y la reacción cristiana, Barcelona, 1993.

3. AME, Manual de Consells, 1, 23-3-1371. 
Este recurso a la celebración de procesiones invocando la misericordia y protección divina era habitual en la época y no hacía sino testimoniar la ineficacia y lentitud de los sistemas ofensivos y defensivos municipales. Lo único que quedaba era confiar en la bondad de Dios para que alejara el peligro, fuese un ataque musulmán o una plaga de langosta. Esto es lo que se volvió a hacer el 27 de marzo de 1380, una procesión de tres días, para librarse del peligro granadino ${ }^{4}$. El peligro no debió ser muy real, por cuanto todo se quedó en simples rogativas y no hubo ningún intento por parte de los jurados de reunir la fuerza armada local.

Fue entre mediados de noviembre de 1383 y abril de 1384 cuando se vivió el momento de mayor tensión en Elche en sus indirectas relaciones bélicas con Granada, que llevó a los jurados de la villa, ante el temor de guerra con los musulmanes, a reparar los muros de la villa, destinando para ello la elevada suma de mil sueldos. La puesta a punto de las murallas era otra de las habituales medidas que se tomaban en caso de un posible ataque del enemigo, ya que lo habitual era que por descuido y falta de recursos económicos las fortificaciones urbanas se encontraran en un estado bastante precario, si no general sí en algunos de sus tramos, por lo que había que cerrar e impermeabilizar el perímetro urbano para evitar cualquier invasión por sorpresa. Lo malo de estas situaciones de emergencia era que resultaban muy costosas y difíciles de asumir por un municipio siempre corto en sus presupuestos o un vecindario poco dispuesto a contribuir en este tipo de cargas vecinales. Esta medida se complementó con la instalación de un sistema de vigilancia permanente en la muralla, una vez que se comprobó la veracidad de la amenaza granadina.

La frontera meridional permaneció en calma los dos meses siguientes, hasta que el día de Navidad, ante las noticias de que el rey de Granada había dado orden a las localidades fronterizas de su reino que procedieran a atacar y damnificar las posiciones del rey de Aragón, para lo cual estaba preparado un contingente de peones y jinetes, los jurados ilicitanos escribieron al adelantado de Murcia, Alfonso Yáñez Fajardo, con el fin de que les mantuviera informados de cuanto sucediera en tierras granadinas y como verdader catòlich christià les dirà la verdad ${ }^{5}$.

La amenaza granadina se hizo realidad a finales de diciembre, pues en una carta del adelantado de Murcia del 2 de enero de 1384 se alude a los asaltos y robos cometidos hacía unos días en Murcia y en la tierra del rey de Aragón por los granadinos, lo que motivó el establecimiento de atajadores

4. AME, Manual de Consells, 1, 27-3-1380.

5. AME, Manual de Consells, 1, fol. 322 r-v. J. Hinojosa Mon'ralvo, «Cristianos, mudéjares y granadinos en la gobernación de Orihuela», IV Coloquio de Historia Medieval Andaluza. Las relaciones exteriores del reino de Granada, Almeria, 1988, pp. 323-342. 
en el término de Lorca, desde el mar al puerto del Conejo. El adelantado solicitaba la colaboración económica de los ilicitanos en el pago de los atajadores, a lo que Elche fue dando largas.

La solicitud de las autoridades reales y municipales de Orihuela a Elche para la defensa común de la gobernación se plasmó en la reunión habida en Murcia en las casas del adelantado y acudieron a ella los representantes de Murcia, Orihuela, Elche (Jaume Junyer y Garcia Sánchez de Lorca), Alicante, así como los de Elda y Novelda, señorío de la reina, adoptándose la decisión de establecer una serie de exploradores durante dos meses, corriendo los municipios valencianos de la frontera con la cuarta parte del gasto. Su distribución fue la siguiente: los de Orihuela pagarían a cuatro hombres; los del valle de Elda a tres, Elche, Crevillente, Alicante y Monforte otros tres hombres, de los cuales correspondian a Elche y Crevillente el pago de un hombre y medio. También los jurados ilicitanos acordaron colocar una vigilancia sin rondas, salvo que llegaran noticias amenazadoras. El 22 de enero se dispuso el establecimiento de centinelas y de rondas nocturnas, además de disponer la compra de 50 ballestas, 50 corazas, 50 bacinetes y 50 escudos pavesos. Esta medida se complementó con otras referentes a la provisión y abastecimiento de víveres, prohibiéndose la saca de trigo y harina, productos básicos, de la villa.

Las medidas militares se completaron con otras de carácter religioso, de fuerte contenido simbólico, como fueron las habituales procesiones y misas para pedir al Altísimo que alejara el peligro musulmán. Las actas municipales, que son nuestra fuente de información, nos narran que en aquellas procesiones predicó un fraile, que exhortó a que se pusieran cruces en los caminos de entrada a la villa, como era tradicional en el reino de Valencia, que era senyal d'habitació de christians. La Cruz frente a la Media Luna. Podemos imaginarnos el tono exaltado, mesiánico y apocalíptico de aquel predicador clamando en defensa de la Cristiandad y tratando de aglutinar la tensión del momento contra el infiel, así como el miedo que flotaría en el ambiente del arrabal mudéjar de la morería de Elche, pues no era raro que en estas ocasiones de exaltación religiosa la belicosidad de las masas se trasladase contra los barrios de las minorías religiosas, judíos o musulmanes, como sucedió con el asalto a la morería de Valencia en 1455. En Elche, por fortuna, no se llegó a tal extremo y la morería no sufrió ningún envite de sus vecinos cristianos.

Sin embargo, la propuesta del fraile de erigir cruces en los caminos sí que fue escuchada y atendida por los jurados de Elche, que en esa reunión del 22 de enero acordó que se hiciera una creu de pedra, onesta e bella, camí d'Oriola, llà sia acordat que millor estia... De este modo el patrimonio artístico de Elche se vio enriquecido con la bella cruz gótica, conservada hasta nuestros días, cuyo sentido real y simbólico no era otro que reafirmar la fe en el cristianismo de los vecinos de la villa. 
Transcurrió mes y medio de incertidumbre, hasta que el 13 de marzo, ante la noticia de que los granadinos iban a atacar, las autoridades se aprestaron a la defensa de la villa y su término mediante la organización de un sistema de cuadrillas, integradas cada una por dos hombres de a caballo y tres peones con sus cuadrilleros, que serían los jefes. Su misión era acudir allí donde estuviera el peligro y perseguir a los almogávares. De las cuadrillas formarían parte también algunos mudéjares ilicitanos, bajo la supervisión del procurador-baile de Elche, el justicia y los jurados.

Se dispuso también por los jurados un servicio de intendencia para la compañía que saliera a perseguir a los almogávares, que estaría integrado por una acémila cargada con pan, vino, alpargatas y cebada, testimonio de lo que sería la alimentación de campaña de esta milicia.

Casi cuatro meses después de que llegaran las primeras noticias del peligro granadino, éste se hizo realidad a mediados del mes de abril, y el día 16 repicaron las campanas de la iglesia de Santa María y la milicia concejil salió para perseguir el rastro de los almogávares, produciéndose el encuentro armado entre granadinos e ilicitanos en el término de Elche, en el camino entre Elche y Alicante. El grupo nazarí estaba integrado por seis hombres, de los cuales cuatro murieron y los dos restantes cayeron prisioneros en manos de los ilicitanos. Su suerte fue trágica, ya que, según acuerdo unánime tomado en reunión pública del Consell y del pueblo ilicitano, fueron condenados a la pena capital, ya que volien que'ls dits moros morisen ${ }^{6}$. Era la desgraciada consecuencia de tanta tensión acumulada en el seno de una sociedad cristiana de frontera, que sentía la amenaza granadina como una realidad cotidiana y que descargaba sus iras y deseos de venganza mal contenidos con aquellos prisioneros. Un claro testimonio de lo que ha sido llamado "neurosis granadina".

La victoria de los ilicitanos fue completa, ya que los vecinos de Elche, mandados por el justicia, sólo sufrieron la pérdida de un caballo, cuyo importe abonaría el municipio a su dueño con el dinero que se obtuviera de la venta de los dos prisioneros, que, a su vez, eran reclamados por el gobernador de Orihuela.

\section{LAS INCURSIONES GRANADINAS EN EL SIGLO XV}

Tras este incidente la paz, relativa, volvió a la frontera terrestre meridional del reino de Valencia, aunque hubo dos incursiones armadas por mar en 1384 y 1400, así como bastantes más por la frontera terrestre, de ellas la más grave fue la de principios de 1386 en que los granadinos saquearon las co-

6. AME, Manual de Consells, 1, fol. $369 \mathrm{v}$. 
marcas de Alicante, Biar y Alcoy ${ }^{7}$. Los continuos asaltos de los collerats y malhechores granadinos y de los almogávares cristianos crearon tal inquietud en toda la frontera valenciana y castellana que llevó a la formación de una hermandad entre las aljamas musulmanas y los municipios cristianos, basada en la responsabilidad colectiva de la comunidad cristiana hacia la musulmana y viceversa a la hora de costear los rescates de los cautivos o de perseguir a los bandoleros, estudiada con detalle por A. Nieto, J. Torres Fontes y M. T. Ferrer ${ }^{8}$.

La presencia del almogávar granadino era un hecho casi cotidiano en nuestras tierras, y todos los años se producían correrías o avisos de intentos de penetración granadina, hasta que en 1405 la firma de paces entre Aragón y Granada parece que produjo un descenso de esta actividad violenta, que de nuevo se agravó en 1409, sobre todo por la acción de un renegado, Nicolás Lorenzo, que se había refugiado en Granada y conocía bien el terreno. La tregua firmada entre Granada y Castilla la utilizaron los granadinos para rescatar sus cautivos presos en Orihuela, abonando por ellos el precio de compra, de acuerdo con lo que estipulaban los pactos, mientras que el rescate de los oriolanos presos en Granada fue mucho más lento. No sabemos si había cautivos ilicitanos en el corral de Granada por estas fechas, aunque cabe pensarlo en sentido afirmativo.

En estas entradas nazaríes los habitantes de los caseríos aislados o los viajeros eran uno de sus objetivos preferidos, como le sucedió en 1414 a Pere Domingo, vecino de Elche, quien yendo con su padre por la cañada de la Polvorosa, en el término ilicitano, oyeron los gritos de un pastor que perseguía a un "moro", que no pudo ser capturado, aunque se sospechaba que formaba parte de una banda de almogávares granadinos ${ }^{9}$. Peor suerte tuvo Pascual Corcoles, vecino de Elche, que fue apresado entre Alicante y Monforte en 1414, y quedó preso en Granada, siendo propuesto su rescate conjuntamente por Elche, Orihuela y Alicante ${ }^{10}$. El 24 de agosto de ese año llegó a Elche, desde Alicante, la noticia de que los granadinos habían asaltado el molino de la vecina localidad de Aspe. A pesar de estos episodios, sin embargo, como señala Roser Salicrú, desde el ascenso al trono de Yusuf III, en mayo de 1408, hasta el destronamiento de su hijo, Muhammad VIII, en

7. M.T. FERrer I MALLOL, La frontera amb l'Islam en el segle XIV, p. 169.

8. A. NiEro, «Hermandad entre las aljamas de moros y las villas de la gobernación de Orihuela en el siglo XV», Primer Congreso de Historia del País Valenciano (Valencia, 1971), II, Valencia, 1980, pp. 749-760; J. TORRES FONTES, «La hermandad de moros y cristianos para el rescate de cautivos», Actas del I Simposio Internacional de Mudejarismo, Madrid-Teruel, 1981, PP. 499-508; M. "T. FERRER I MALLOL, La frontera amb l'Islam en el segle XIV, pp. 196-222.

9. AME, Manual de Consells, 2, sin foliar, 2-1-1414.

10. J. Hinojosa Mon'talvo, Cristianos, mudéjares y granadinos, p. 332. 
marzo de 1419, Granada vivió una etapa de paz aparente, y ello se dejó sentir también en la tranquilidad en la frontera sur del reino de Valencia ${ }^{11}$.

En cambio, a comienzos del mes de septiembre de 1420 vuelve a reaparecer la empresa militar de envergadura contra estas comarcas, dirigida o auspiciada por el rey de Granada Muhammad IX. La vía de transmisión de la noticia era la habitual, césde el reino de Murcia a Orihuela y desde aquí a Elche, y se decía que el rey de Granada estaba reuniendo jinetes y peones en Baza para entrar a saquear el reino de Aragón. Hasta aquí se trataría de una más de las tantas noticias que en estos siglos medievales llegaron a la gobernación de Orihuela de movimientos de tropas granadinas. Lo interesante de esta nueva empresa nazarí es que el objetivo del rey de Granada era recollir los moros de la terra e de menarsen aquells en la terra del dit rey de Granada, y más en concreto los de la morería de Elche, dado que los granadinos, según se expuso ante jurados y consejeros, pensaban venir directos a esta vila, per çò com és terra plana, e combatre aquella ${ }^{12}$. Se retomaba así la vieja práctica, de finales del siglo XIII y principios del XIV, de aprovechar las incursiones en territorio cristiano para regresar al reino de Granada con mudéjares valencianos, en particular de las aljamas meridionales, y cuyos ejemplos más espectaculares fueron las ya citadas entradas del caudillo Ridwan. En el caso que ahora nos ocupa todo apunta a la veracidad de intenciones del monarca granadino, aunque no sabemos si ello se correspondía con un deseo real de los mudéjares ilicitanos de marchar a Granada de forma voluntaria, o si serían llevados a la fuerza. Lo cierto es que son años de inquietud entre los mudéjares valencianos y en 1418 Alfonso el Magnánimo ratificaba la medida adoptada por su antecesor en el trono, Martín el Humano, restringiendo la libertad de viajar de los musulmanes valencianos. De haberse llevado a cabo y haber triunfado la incursión qué duda cabe que hubiera supuesto un duro golpe para la confianza de los cristianos de la gobernación de Orihuela, ya que la morería de Elche era la más importante de todo el territorio. Parece, sin embargo, que todo quedó en un rumor.

Creo que hay una clara conexión entre este intento del rey de Granada de llevarse a los mudéjares de Elche y las emigraciones clandestinas de musulmanes valencianos hacia el reino de Granada, y que se corresponden con la agitación reinante en las morerías valencianas, propiciada sin duda por Muhammad IX, que era visto por muchos mudéjares valencianos como su señor natural y al que se consideraban unidos por lazos religiosos.

A lo largo de la década de los años veinte, aunque no hubo ninguna entrada del ejército granadino en el término de Elche, sí que hubo algunos inci-

11. R. SALICRÚ i LLUCH, Relacions de la Corona d'Aragó amb el regne de Granada al segle XV (14121458), Barcelona, 1996, Tesis doctoral inédita, vol. I, p. 300.

12. AME, Manual de Consells, 3, 1-9-1420. 
dentes protagonizados por individuos aislados o en grupo, de cuya suerte adversa nos informan las actas municipales, ya que una de las medidas utilizadas por los jurados para combatir el peligro almogávar era recompensar económicamente a aquellos que presentaran las cabezas de estos bandoleros musulmanes. Con ello se buscaba la ejemplaridad del castigo, que sirviera de aviso para cuantos se atrevieran a franquear las fronteras cristianas en son de guerra, incluso para que los propios mudéjares valencianos se lo pensaran dos veces antes de colaborar con sus correligionarios de Granada.

Ya hay noticias de estas recompensas a principios de la centuria, y el 20 de julio de 1400 se dieron cinco florines de oro por cinco cabezas de musulmanes que trajeron unos lorquinos, a los que se sumaron otros dos florines el 28 de agosto por dos cabezas de "moros" que se trajeron el día de la Virgen de Agosto. En septiembre de 1420 las autoridades municipales ilicitanas dieron a los hermanos Antoni y Berenguer de Quexans y a Antoni Fira, menor, 12 florines por Albageri, "moro de Vera", capturado en el término de Elche, que fue ahorcado en unas horcas de madera que se levantaron en la plaza de Santa Lucía después de ser juzgado por el lugarteniente del gobernador ${ }^{13}$.

En 1421 fueron dos lorquinos los que trajeron de Granada cuatro cabezas de "moros", entre ellas la del temido y buscado renegado conocido como Palomino, un individuo que, gracias a su conocimiento de la comarca, había causado grandes daños y cuya captura era anhelada por las autoridades cristianas $^{14}$. Además de las citadas se presentaron ante los jurados de Elche en esta década dieciséis cabezas de granadinos gratificadas, por lo general, cada una con un florín y testimonian la inquietud que se vivía en tierras murcianas y del mediodía valenciano. Aunque la paz estaba vigente de forma oficial entre Granada y Aragón, ello no excluía los asaltos, robos e incursiones de almogávares de uno y otro signo. Aledo, Mula, Elda, Orihuela, son localidades donde se produjeron tales muertes, a las que se podrían sumar la propia Elche, en cuyo término se produjeron también algunos ataques, como el sufrido en junio de 1428 por el zapatero Antoni Creus junto a otros cristianos cuando desde Aspe se dirigía a Crevillente por almogávares granadinos, siendo conducido a Granada y teniendo que rescatarse por la suma de 170 florines ${ }^{15}$.

La alarma saltó de nuevo el 26 de octubre de este año, cuando los jurados recibieron noticias de que en Basta, en el reino de Granada, se reunían más de 1.500 "moros de a caballo" y otros 10.000 infantes para atacar el reino de Murcia y la gobernación de Orihuela, aunque el ataque no se pro-

13. AME, Manual de Consells, 4, 1-9-1420.

14. AME, Manual de Consells, 4, 1421.

15. AME, Manual de Consells, 6, 26-6-1428. 
dujo, en noviembre entraron compañías de "moros" por la terra, que cabe interpretar como la gobernación, y al menos cuatro musulmanes resultaron muertos, pues sus cabezas, como ya vimos, fueron entregadas a los jurados, aunque no sabemos si formaban parte de dichas compañías o de alguna partida aislada.

En esta década de los años veinte hubo otros avisos de posibles entradas de almogávares en octubre de 1428 y febrero de 1429, cuando llegó a Elche una carta del gobernador general de Orihuela, avisando de que había tenido noticias de una posible incursión de musulmanes granadinos hacia la frontera de Lorca ${ }^{16}$.

La última noticia de una amenaza granadina sobre Elche es del 27 de septiembre de 1450 , en que llegó la noticia de que 40.000 granadinos, de ellos 4.000 jinetes, se disponían a atacar el sur del reino de Valencia. Según estas informaciones el grueso de las tropas estaba reunido en los Vélez (Belliços), mientras que otra parte de las mismas -según se decía- estaría ya en la frontera de Castilla.

Las autoridades ilicitanas parece que se tomaron muy en serio la amenaza de ataque, o al menos eso parece deducirse de la amplitud de las medidas tomadas por los jurados, que iban desde recoger a los vecinos del arrabal y de la morería intramuros de la villa, a la decisión de acaparar provisiones, así como la preparación de armamento adecuado, entre el que figuraban ballestas y piezas de artillería, como bombardas, amén de limpiar los fosos y llenarlos de agua. El 2 de enero de 1451 se supo la toma de Molina de Segura por los musulmanes, lo que causó un fuerte impacto entre los jurados ilicitanos, sobre todo si tenemos en cuenta la magnitud de la catástrofe con la captura de 140 cristianos, entre ellos 35 ó 40 hombres de Orihuela que acudieron a auxiliar a Molina, así como de la destrucción del lugar (enderrocat e aplanat), a lo que se añadía la toma de 15 ó 16 lugares del valle de Ricote, cuyos habitantes musulmanes fueron apresados, los lugares derruidos y todos, cristianos y musulmanes, conducidos como cautivos al reino de Granada. Lo peor era que se temía que los granadinos pudiesen proseguir su incursión profundizando hasta llegar al mediodía del reino de Valencia, apoderándose de las poblaciones donde residían mudéjares. Y éste era precisamente el caso de Elche, que contaba con la morería más poblada del sur valenciano. Por otra noticia posterior dada por los jurados en una de sus reuniones parece que los atacantes de Molina fueron 5.000 jinetes y más de 10.000 infantes.

El ataque granadino no pasó de un proyecto, pero quedó el impacto psicológico producido por el ataque a Molina. El miedo al granadino, al moro, incluso al de casa, se extendía por la sociedad valenciana, y esto supieron aprovecharlo nuestras autoridades para rearmarse y para poner a punto

16. AME, Manual de Consells, 6, 16-2-1429. 
una villa que como Elche estaba en unas condiciones más que precarias desde el descalabro sufrido en hombres y armas en la guerra castellana de 1430.

\section{ELCHE EN LA GUERRA DE GRANADA}

La participación de Elche en la guerra de Granada fue modesta si la comparamos con otras localidades valencianas, como Orihuela o la propia capital, y siempre en función de sus relaciones con el señor de la villa, don Gutierre de Cárdenas, que sí participó directamente en la empresa. Por causa de ello, las autoridades locales de Elche, cuando Cárdenas estaba al servicio del rey en el sitio de Málaga, el 5 de agosto de 1487, dispusieron que se le enviaran dos cahíces de trigo convertidos en harina, 150 cahíces de cebada y cien pares de gallinas, corriendo el clavario con los gastos ${ }^{17}$. Estas vituallas serían transportadas por los jornaleros del muro al puerto ilicitano del Cap del Aljup. Una semana después, el día 12, Pere Gonçalves y Pere de Mella, mensajeros de Elche, ofrendaron su presente a Gutierre de Cárdenas, quien los recibió con toda amabilidad y mostró su satisfacción por dicho obsequio, regresando el 24 de agosto a Elche.

Un nuevo obsequio se le hizo al comendador Cárdenas el 30 de julio de 1489 enviándole cien pares de pollos y toda la fruta que se pudiera conseguir en Elche, de forma que pudiera regalar su paladar mientras estaba en el sitio de Baza ${ }^{18}$. En definitiva, muchos pollos y pocas armas.

\section{LAS REPERCUSIONES DEL PELIGRO GRANADINO EN ELCHE}

La amenaza armada de los granadinos sobre las tierras del mediodía valenciano y en concreto sobre la villa de Elche tuvo muy variadas consecuencias, en muy diversos terrenos. Comenzando por la demografía podemos decir que la incidencia de estos ataques y correrías de los ejércitos y almogávares nazaríes fue desigual en el tiempo y sobre las comunidades musulmana y cristiana. La primera de ellas, la mudéjar, se vio muy afectada en las primeras décadas del siglo XIV por las incursiones del caudillo Ridwan en 1331, que a su regreso a Granada se llevó consigo, de grado o por fuerza, a muchos mudéjares ilicitanos, aunque su cuantía exacta es imposible de precisar, si bien las fuentes oficiales, es decir la carta que Llop Ximenis de Perencisa, lugarteniente del procurador del reino de Valencia, señalaron que

17. AME, Manual de Consells, 18, fol. 25 r.

18. AME, Manual de Consells, fol. $49 \mathrm{v}$. 
el ejército nazarita se llevó 1.500 cautivos, a los que siguieron 400 mudéjares de Elche y otros lugares, que colaboraron con los invasores entregándoles 800 acémilas para transportar el botín ${ }^{19}$. El cronista oriolano P. Bellot daba la cifra de 1.500 los "moros" de las tierras al sur de Jijona que marcharon a Granada, sobre todo del valle de Elda, pero M. ${ }^{a} \mathrm{~T}$. Ferrer desconoce de dónde saca dichos datos, que no son los de Ximenis de Perencisa, ciertamente.

Algunos de estos musulmanes que marcharon a Granada se adaptaron a su nueva patria y allí reorganizaron sus vidas en el seno del único Estado islámico que quedaba en suelo peninsular. Otros, por el contrario, fueron obligados a ir a Granada a la fuerza y luego quisieron retornar a su anterior hogar en Elche, para lo cual el infante Ramón Berenguer, señor de Elche, que no estaba dispuesto a perder tan elevado número de vasallos y ver disminuida su renta feudal, envió un mensajero a Granada para pedir el retorno de veintitrés de estos musulmanes ilicitanos. El objetivo se consiguió, pero con tan mala fortuna que al regreso a Elche fueron capturados por almogávares cristianos, que vendieron a los mudéjares citados como cautivos en Mallorca, aunque con el tiempo se consiguió rescatarlos ${ }^{20}$. En lo que quedaba de época medieval los mudéjares ilicitanos vivieron tranquilamente en su marco de la morería de la villa y no hay noticias de que fueran víctimas de las agresiones de sus correligionarios del reino de Granada.

En cuanto a los cristianos es imposible cuantificar, ni siquiera por aproximación, las consecuencias que para la demografía local tuvieron las correrías de tropas regulares y almogávares nazaríes. Ya vimos que el mayor desastre se produjo en la incursión de Ridwan, con 1.500 cautivos, de Elche y Guardamar principalmente, aunque no sabemos el número exacto de ellos que eran ilicitanos. Luego a lo largo de estos dos siglos un número imposible de precisar de vecinos fueron apresados ocasionalmente por los almogávares nazaríes en sus entradas por estas tierras de la gobernación y terminaron cautivos en Granada, como ya vimos. Pero cualquier intento por cuantificar datos es inútil, ya que sólo noticias aisladas nos han llegado, aun cuando cabe pensar que el fenómeno no tuvo graves consecuencias en la demografía local.

El rescate de estos vecinos cautivos fue una constante preocupación para los familiares y las autoridades, que en Elche, como en otras localidades fronteras, mantenían un bací de catius, una limosna para el rescate de estos prisioneros, a base de las donaciones voluntarias de los particulares. También los jurados ayudaban económicamente al rescate de sus convecinos, en ocasiones de forma conjunta con Alicante y Orihuela, como se hizo en

19. M. ${ }^{a}$ T. FERRER I MALLOL, La frontera amb l'Islam en el segle XIV, pp. 128-129.

20. Ibidem, p. 129. 
1414 con Pascual Corcoles, vecino de Elche. Otras veces la iniciativa de rescatar a los vecinos cautivos partía de algún particular, que dejaba algunos fondos para tal fin, como en 1455 hizo Guillem Pérez de Sarrió, que dejó ciertos censos para poder redimir a cautivos de su linaje, o de no haberlos, de otras personas pobres de la localidad.

La amenaza granadina fue causa justificada de la colaboración entre municipios de la gobernación de Orihuela, y también con la ciudad de Murcia, ya que todos ellos se veían afectados por una problemática similar de inseguridad territorial, cristalizando en el envío de correos, misivas y medidas conjuntas de colaboración militar. Hay bastantes ejemplos de ello, desde la reunión en 1384 en Murcia de los representantes de esta ciudad con los de Lorca, Orihuela y Elche para establecer atajadores que avisaran del peligro de incursiones granadinas, a la hermandad entre aljamas y municipios de fines del siglo XIV, ya comentada.

Los granadinos y sus ataques fueron también utilizados por las autoridades de Elche como excusa, más o menos legal, para mantener en relativo buen estado el sistema defensivo de Elche. Era una carga onerosa para la villa y aunque existían algunos recursos fiscales destinados a ello, siempre eran insuficientes y los vecinos se mostraban reacios a las contribuciones desinteresadas, por mucho que ello redundara en su beneficio o se apelara al bien común. La gente no estaba para gastos extraordinarios. De ahí que la primera medida que adoptaban los jurados era la de proceder a reparar aquellas zonas de la muralla más degradadas, como sucedió en 1384, 1400, 1420, 1428 ó 1451, por citar unos años. Esta medida solía acompañarse con otras de limpieza de los fosos, alcantarillas y desagües, con frecuencia obstruidos por las inmundicias que arrojaba la gente y que hacía inútil su funcionalidad defensiva. También se establecían rondas, atalayas y vigilantes en el perímetro murado y las puertas de acceso a Elche, variando su número según el índice de peligrosidad, calculado por el justicia y los jurados en base a las noticias procedentes del exterior. En todos estos gastos extraordinarios los mudéjares del arrabal -la morería- contribuían con la tercera parte, aunque no siempre lo hacían de buena gana.

Esta situación de tensión militar permitía mantener encuadrados a los ilicitanos en la milicia vecinal, de carácter no permanente y limitada a las ocasiones de peligro. Los habitantes de la villa estaban registrados en un libro de vigilancia o de cuadrilla, según se tratara de misiones defensivas o de apellido. En marzo de 1384, por ejemplo, estas cuadrillas las integraban dos hombres de a caballo y cuatro de a pie. La llegada del enemigo se avisaría a toque de campana, sistema también utilizado para reunir el apellido. El que no quisiera ir o regresara antes de que se concediera la licencia sería castigado con una multa de 30 sueldos. El municipio costeaba una acémila para las provisiones de la milicia, formando el servicio de intendencia de la misma. 
No es posible precisar por falta de datos seriados las repercusiones de este peligro granadino en la hacienda municipal, pero tampoco parece que desequilibrara el presupuesto municipal, y los gastos en salarios de hombres armados, víveres o armas no fueron excesivos, salvo en algún año puntual. Hay que recordar también, que ante las noticias de posibles agresiones externas, los jurados prohibían la salida de trigo y harina de Elche, con el fin de evitar que quedara desabastecido el mercado local.

Cuantificar las pérdidas que en la economía local, sobre todo en la agricultura y la ganadería, causaron estas incursiones, es tarea vana, aunque noticias sueltas no faltan. Las más precisas se refieren a la campaña de Ridwan en 1331, cuando en su retirada hacia Granada taló las huertas y destruyó las cosechas de Elche y Orihuela, llevándose 800 yeguas, 2.000 vacas y abundante ganado menudo, además de 20.000 cahíces de trigo que los mercaderes de Valencia y de otros lugares habían reunido en Elche, así como otros bienes muebles, cifras que $M .{ }^{a} T$. Ferrer considera ajustadas a la realidad ${ }^{21}$.

Aunque a finales de la Edad Media parece que las relaciones entre las comunidades mudéjar y cristiana de Elche no fueran malas, el peligro granadino generó siempre una desconfianza y un recelo hacia el "moro" de Elche y de otras localidades vecinas, que fue mayor en las primeras décadas del siglo XIV, cuando las relaciones entre Granada y Aragón atravesaron momentos críticos a causa de los conflictos bélicos (cruzada contra Almería en 1309, cruzada de Alfonso el benigno contra Granada, expediciones de Ridwan...), ya que los mudéjares valencianos eran considerados cómplices de estos ataques granadinos. Por ejemplo, después del asedio y saqueo de Elche por Ridwan en octubre de 1331, a principios del año 1332 los espías renegados transmitían información sobre el próximo objetivo de Ridwan, que sería Orihuela, Elche y Alicante, que los musulmanes de estos lugares pensaban entregarle. Fuera o no realidad este propósito, el reciente desastre cristiano estaba tan cercano, con la huida de los mudéjares de Elche, que nadie dudaba de que así pudiera ser, lo que no favorecía a un entendimiento entre miembros de ambas comunidades.

La "psicosis granadina" no se extinguió con el paso del tiempo, aunque al menos se atenuó, pero este miedo siempre subyacía en muchas de las actuaciones de los jurados de Elche, en particular aquéllas que tenían que ver con la defensa de la villa y de sus vecinos. Para ellos Elche era un islote cristiano entre musulmanes y bien claro lo expuso en 1400 el Consell cuando esgrimió que la dita vila d'Elig és a manera de castell e poblada e edificada entre moros para justificar el cierre de la puerta de la villa por la noche, que hasta entonces permanecía abierta. Dado el mal estado de los muros, derruidos en algún punto, se dispuso que dicha puerta fuera controlada por el justicia y

21. M.'T. FerRer I MALLOL, La frontera amb l'Islam en el segle XIV, p. 128. 
que no pudiera entrar por la noche en Elche ningún musulmán, debiendo ir acompañado de un cristiano cuando fuera a hacer sus negocios. Una vez más cualquier excusa era válida para marginar y discriminar al mudéjar ilicitano, ya de por sí excluido y confinado a vivir en el arrabal de la morería. Ahora se le ve como un posible traidor, como sospechoso de poder traicionar a los cristianos y entregar la villa a los granadinos, y se le prohíbe entrar por la noche en la localidad.

El miedo al "moro" fue utilizado por las autoridades para acentuar la religiosidad del vecindario, para reafirmar su cristianismo frente al Islam del "otro", del enemigo, a la vez que establecían unos vínculos de comunicación y de control entre los grupos dirigentes y las clases subordinadas. Así, en 1384 los jurados, temerosos de una invasión, acordaron celebrar procesiones y misas para que nostre Senyor Déu guart aquest poble de moros. Las predicaciones de un fraile caldearían los ánimos y el resultado fue la construcción de una cruz de piedra en el camino de Orihuela, la manifestación externa y perdurable en el tiempo del cristianismo de los vecinos de la villa, frente a los musulmanes del arrabal o de las localidades vecinas de Crevillente y el valle de Elda, de población mudéjar casi en su totalidad. Era el "paraguas" divino que debía proteger a Elche de futuros ataques.

\section{EPÍLOGO}

En 1492, la conquista por los Reyes Católicos de Granada, el último bastión del reino nazarí, puso fin a la amenaza granadina para las comarcas meridionales del reino de Valencia, y la seguridad llegó por primera vez a sus caminos y a los hogares de sus vecinos. El fenómeno debió ser tan llamativo que captó la atención del viajero alemán Jerónimo Münzer, que por entonces recorría nuestra geografía, y no dudó en calificar el itinerario entre Alicante y Elche como "llanura estéril, hasta hace muy poco peligrosa por causa de los ladrones moros" 22 . La seguridad abría insospechadas posibilidades de desarrollo y prosperidad en el alborear de los Tiempos Modernos a estas tierras de los reinos de Valencia y Murcia, aunque la paz y la tranquilidad no fue completa, pues el peligro vendría en adelante del mar y de los piratas norteafricanos. Pero esa es ya otra historia.

\section{RESUMEN}

Desde finales del siglo XIII Elche pasó a ser tierra de frontera con el reino de Granada, siendo objeto de numerosas incursiones por parte de los

22. Viajes de extranjeros por España y Portugal, edic. J. García MerCadal, Madrid, 1952, I, p. 345. 
granadinos, contando con el apoyo de la población mudéjar de la zona. También hubo ataques por mar a cargo de los piratas granadinos, todo lo cual creó un estado de inquietud en la zona y una actitud de recelo hacia los mudéjares. Muchos vecinos de Elche cayeron cautivos y hubo que rescatarlos, en tanto que los frecuentes avisos de la amenaza de ataques desde Granada movilizaban a la milicia local y obligaban a adoptar medidas defensivas. La presentación de cabezas de granadinos era recompensada económicamente por las autoridades de Elche.

\section{ABSTRACT}

From the end of the 13th century Elche became a frontier land with the Grenada Kingdom, being the target of a number of raids carried out by the people from Grenada who had the support of the Mudejar population living in the area. There were also attacks from the sea by the Grenada pirates causing that a feeling of worry spreaded among the people of the area and the existence of a distrust attitude towards the Mudejar people. Many inhabitants of Elche were made captive and it was necessary to rescue them, while the warning of new attacks from Grenada made the local soldiery be mobilized forcing to adopt defensive measures. The presentation of people from Grenada heads were economically rewarded by the Authorities of Elche. 